\title{
ESSAY
}

\section{Asilomar 1975: DNA modification secured}

\section{The California meeting set standards allowing geneticists to push research to its limits without endangering public health. Organizer Paul Berg asks if another such meeting could resolve today's controversies.}

T oday, the benefits of genetic engineering, and the risks and ethical dilemmas that it presents, are part of everyday public discourse, thrashed out in newspaper columns and by politicians and commentators everywhere. In the early 1970s, it was a very different picture. Scientists were only just learning how to manipulate DNA from various sources into combinations that were not known to exist naturally. Although they were confident that the new technology offered considerable opportunities, the potential health and environmental risks were unclear.

The people who sounded the alarm about this new line of experimentation were not politicians, religious groups or journalists, as one might expect: they were scientists. They called for a worldwide moratorium on the work, followed by an international conference of experts at which the nature and magnitude of the risks could be assessed. At that gathering, the International Congress on Recombinant DNA Molecules, held at the Asilomar Conference Center in Pacific Grove, California, in February 1975, it was agreed that the research should continue but under stringent guidelines. The conference marked the beginning of an exceptional era for science and for the public discussion of science policy.

\section{Cancer-carrying bacteria}

Some of the concerns about recombinant DNA experimentation stemmed from my own work with the Simian Virus 40 (SV40), which can produce tumours in rodents. My aim was to use SV40 to introduce new genes into mammalian cells. Because the DNA of SV40 can integrate into the chromosomes of infected cells, I reasoned that any 'foreign DNA' associated with it would also become part of the infected cell's genetic make-up, and consequently we might be able to study the foreign DNA's expression in mammalian cells. To test this, we inserted a segment of DNA containing three Escherichia coli genes responsible for the metabolism of the sugar galactose into the genome of the Simian Virus.

Several scientists feared that bacteria carrying SV40 DNA might escape and cause cancer in people infected, so we chose to defer our experiments until we could be sure that the risk was nonexistent. Most researchers, like me, acknowledged that the new technology opened extraordinary avenues for genetics and could ultimately lead to exceptional opportunities in medicine, agriculture and industry. But we conceded that unfettered pursuit of these goals might have unforeseen and damaging consequences for human health and Earth's ecosystems.

Earlier, in mid-1974, I had led a committee that communicated those concerns to the president of the US National Academy of Sciences and published them in Science, Nature and in Proceedings of the National Academy of Sciences. We recommended a voluntary moratorium on certain recombinant DNA experiments that were considered potentially hazardous. The committee was particularly concerned that introduced genes could change normally innocuous microbes into cancer-causing agents or into human pathogens, resistant to antibiotics or able to produce dangerous toxins.

Scientists around the world hotly debated the wisdom of our call for caution, and the press had a field day conjuring up fantastical 'what if' scenarios. Yet the moratorium was universally observed in academic and industrial research centres. Meanwhile, the public seemed comforted by the fact that the freeze had been proposed by the very people who had helped to develop the technology.

We also proposed an international conference at which scientists and appropriate experts could assess the risks of recombinant DNA technology and devise ways of reducing them. With the backing of the National Academy of Sciences and the National Institutes of Health, I and four others - David Baltimore, Sydney Brenner, Richard Roblin and Maxine Singer - drew up the agenda for the conference. Its main aim was to consider whether to lift the voluntary moratorium and, if so, what conditions to impose to ensure that the research could proceed safely. Non-scientists were also encouraged to join in, and the approximately 140 participants included scientists, lawyers, journalists and government officials.

As might be expected, there was considerable disagreement during the conference about the existence and magnitude of the purported risks. Some biologists and public officials were certain that recombinant DNA research was flirting with disaster and that lifting the moratorium would be a blunder. Others argued that the research was safe. Heated discussions carried on during the breaks, at meal times, over drinks and well into the small hours. I was struck by how often scientists willingly acknowledged the risks in other's experiments but not in their own. Brenner repeatedly warned of the consequences of doing nothing, predicting that such apparently self-serving behaviour would be publicly condemned and that government interference or even legislation would follow.

\section{The turning point}

What turned the debate around was the suggestion to assign a risk estimate to the different types of experiments envisaged, and to apply safety guidelines of varying stringency according to the degree of risk. This system worked on two levels. The first was physical containment, whereby the degree of risk was matched with the type of laboratory facility required. So, experiments with little or no risk could be done on an open bench; those with some risk might require laminar flow hoods; a high risk might necessitate an airlock and a laboratory under negative pressure; whereas experiments using known human pathogens would be either prohibited or restricted to specialized facilities. Brenner suggested this should be supplemented with an additional, biological level of containment to minimize the damage should engineered organisms escape into the environment. Thus in cloning experiments that were judged to be of little or no risk, researchers could work on relatively innocuous organisms such as widely used lab strains of E. coli and Bacillus subtilis; riskier experiments would have to use bacteria that had been genetically modified so they could not survive outside the laboratory.

Participants agreed on the final day of the conference that research should continue, but under stringent restrictions. The recommendations formed the basis of the official US guidelines on research involving recombinant DNA, issued in July 1976 . They have proved remarkably effective.

In the 33 years since Asilomar, researchers around the world have carried out countless experiments with recombinant DNA without 

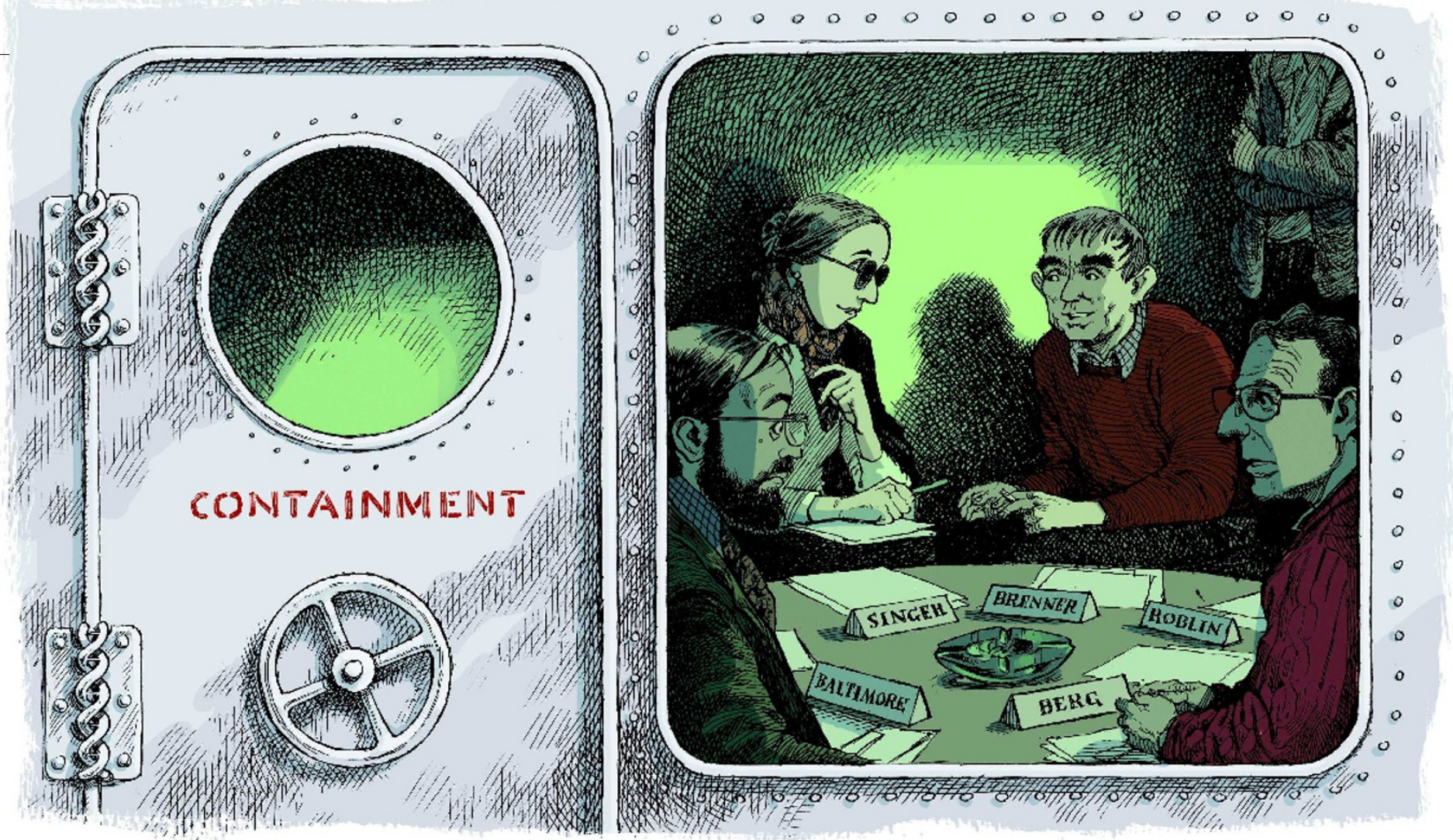

reported incident. Many of these experiments were inconceivable in 1975, yet as far as we know, none has been a hazard to public health. Moreover, the fear among scientists that artificially moving DNA among species would have profound effects on natural processes has substantially disappeared with the discovery that such exchanges occur in nature.

\section{The promised land}

What of the benefits of allowing researchers to continue to work with recombinant DNA? In 1975, many scientists predicted that the technology would soon yield important drugs, industrial products and improved agricultural varieties.

In fact, such developments have taken longer than anticipated. Some have never been realized because identifying the genes responsible for producing certain products or conditions, and learning how to manipulate them usefully has been more difficult than expected. Since the mid-1980s, however, the number of products has risen continually. Genetically modified hormones, vaccines, therapeutic agents and diagnostic tools are enhancing medical practice. Genetically engineered food plants are being grown and sold for consumption in both developed and developing countries. A thriving biotechnology industry has created products, jobs and wealth for scientists and others. Very few Asilomar attendees foresaw this great potential - nor could we have predicted the pace at which our fundamental understanding of biology has grown.

Apart from laying the foundations for an effective safety regime, what else did Asilomar achieve? First and foremost, I feel that scientists were able to gain the public's trust - something that is now much more difficult for researchers working in biotechnology. Because some $15 \%$ of the participants at Asilomar were from the media, the public was well informed about the deliberations, as well as the bickering, accusations, wavering views and ultimately the consensus. Many scientists feared that a public debate would place crippling restrictions on molecular biology, but the effort encouraged responsible discussion that led to a consensus that most researchers supported.

Could an Asilomar-type conference help resolve some of the controversies now confronting scientists and the public - such as over fetal tissue, embryonic stem-cell research, somatic and germ-line gene therapy and the genetic modification of food crops? I believe that it would be much more difficult to organize such an event today. In the 1970s, most of the scientists engaged in recombinant DNA research were working in public institutions and were therefore able to get together and voice opinions without having to look over their shoulders. This is no longer the case - as many scientists now work for private companies where commercial considerations are paramount.

Related to this is that so many issues in science and technology today are beset by economic self-interest and, increasingly, by nearly irreconcilable ethical and religious conflicts, as well as by challenges to deeply held social values. A conference that sets out to find a consensus among such contentious views would, I believe, be doomed to acrimony and policy stagnation.

That said, there is a lesson in Asilomar for all of science: the best way to respond to concerns created by emerging knowledge or early-stage technologies is for scientists from publiclyfunded institutions to find common cause with the wider public about the best way to regulate - as early as possible. Once scientists from corporations begin to dominate the research enterprise, it will simply be too late.

Paul Berg was one of the organizers of the International Congress on Recombinant DNA Molecules held in Asilomar, 24-27 February 1975. $\mathrm{He}$ is Cahill professor emeritus of biochemistry, and director emeritus of the Beckman Center of Molecular and Genetic Medicine, at Stanford University, 279 Campus Drive, Stanford,

California 94305, USA. He received the Nobel Prize in Chemistry in 1980 and the US National Medal of Science in 1983.

e-mail: pberg@stanford.edu

For more Meetings that Changed the World, see www.nature.com/nature/focus/meetings 